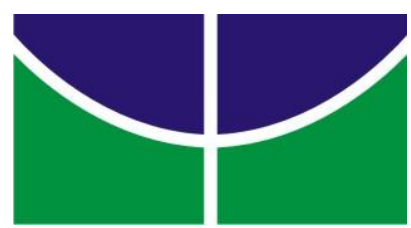

UNIVERSIDADE DE BRASÍLIA

Faculdade de Educação - UAB/UNB/MEC/SECAD

Curso de Especialização em Educação na Diversidade e Cidadania, com Ênfase em EJA

\author{
ARLINDA MARIA ANDRADE DA SILVA \\ LEVI ALVES PORTO \\ MARIA DAS DORES DIAS DE ARAÚJO \\ RAQUEL DE BARÇONETE MAIA DE CARVALHO GUIMARÃES \\ ROSENI DOS SANTOS MIRANDA MENDONÇA
}

A IMPORTÂNCIA DA LEITURA PARA ELEVAR A AUTOESTIMA DOS ALUNOS DE EDUCAÇÃO DE JOVENS E ADULTOS

BRASÍLIA - DF

Julho/2010 


$$
\begin{gathered}
\text { UNIVERSIDADE DE BRASÍLIA } \\
\text { Faculdade de Educação - UAB/UNB/MEC/SECAD } \\
\text { Curso de Especialização em Educação na Diversidade e Cidadania, } \\
\text { com Ênfase em EJA }
\end{gathered}
$$

\title{
A IMPORTÂNCIA DA LEITURA PARA ELEVAR A AUTOESTIMA DOS ALUNOS DE EDUCAÇÃO DE JOVENS E ADULTOS
}

\author{
ARLINDA MARIA ANDRADE DA SILVA \\ LEVI ALVES PORTO \\ MARIA DAS DORES DIAS DE ARAÚJO \\ RAQUEL DE BARÇONETE MAIA DE CARVALHO GUIMARÃES \\ ROSENI DOS SANTOS MIRANDA MENDONÇA
}

Carmenísia Jacobina Aires

Alexandra Pereira da Silva

Projeto de intervenção

BRASÍLIA, DF JULHO/2010 


$$
\begin{gathered}
\text { UNIVERSIDADE DE BRASÍLIA } \\
\text { Faculdade de Educação - UAB/UNB/MEC/SECAD } \\
\text { Curso de Especialização em Educação na Diversidade e Cidadania, } \\
\text { com Ênfase em EJA }
\end{gathered}
$$

ARLINDA MARIA ANDRADE DA SILVA

LEVI ALVES PORTO

MARIA DAS DORES DIAS DE ARAÚJO

RAQUEL DE BARÇONETE MAIA DE CARVALHO GUIMARÃES

ROSENI DOS SANTOS MIRANDA MENDONÇA

\section{A IMPORTÂNCIA DA LEITURA PARA ELEVAR A AUTOESTIMA DOS ALUNOS DE EDUCAÇÃO DE JOVENS E ADULTOS}

Trabalho de conclusão do Curso de Especialização em Educação na Diversidade e Cidadania, com ênfase em EJA, como parte dos requisitos necessários para obtenção do Grau de Especialista na Educação de Jovens e Adultos

Carmenísia Jacobina Aires

Professora-orientadora

Alexandra Pereira da Silva

Tutora-orientadora

Elaine Filomena Chagas Cáceres Vitor

Avaliadora externa

BRASÍLIA, DF JULHO DE 2010 


\section{RESUMO}

Este projeto trata das dificuldades detectadas de leitura, interpretação de texto e da baixa autoestima dos alunos da Educação de Jovens e Adultos que compõe a comunidade escolar na cidade do Novo Gama-GO; essas deficiências, apresentadas pelos alunos, tem dificultado a possibilidade de adquirirem educação de qualidade apresentando bastante desinteresse e pouca motivação para o andamento dos estudos; o objetivo deste Projeto de Intervenção Local será despertar e proporcionar aos estudantes, interesse e motivação para desenvolver a arte da leitura e conhecimentos críticos e reflexivos através da organização de projetos para cada componente curricular, coordenados pelos professores e realizados pelos alunos, que serão apresentados na feira do livro realizadas nas escolas João Gabriel e Lago Azul.

Palavras-chave: Dificuldades de leitura; autoestima; Educação de qualidade; Conhecimentos. 


\section{SUMÁRIO}

1-DADOS DOS PROPONENTES 06

1.1- AUTORES 06

1.2- TURMA 06

2. - DADOS DO PROJETO 06

2.1- TÍTULO 06

2.2- ÁREA DE ABRANGÊNCIA 06

2.3- INSTITUIÇÕES 06

2.4-PÚBLICO AO QUAL SE DESTINA 06

2.5-PERÍODO DE EXECUÇÃO 07

3- AMBIENTE INSTITUCIONAL 07

4- JUSTIFICATIVA E CARACTERIZAÇÃO DO PROBLEMA 08

5- OBJETIVOS 12

5.1-OBJETIVO GERAL 12

5.2-OBJETIVOS ESPECÍFICOS 12

6-ATIVIDADES/RESPONSABILIDADES 12

7- CRONOGRAMA 14

8- PARCEIROS 14

9- ORÇAMENTO 14

10- ACOMPANHAMENTO E AVALIAÇÃO 15

11-REFERÊNCIAS BIBLIOGRÁFICAS 15 


\section{1- DADOS DE IDENTIFICAÇÃO DOS PROPONENTES}

\section{1-AUTORES}

Arlinda Maria Andrade da Silva

3484-7796/ 96376276/ e-mail: arlindandrade@gmail.com

Levi Alves Porto

3797 1895/ e-mail: leviporto73@live.com

Maria das Dores Dias de Araújo

3556 5621/ e-mail: soumaismaria@hotmail.com

Raquel de Barçonete Maia de Carvalho Guimarães

3384-5727/99293745/ e-mail: barconeteguimaraes@gmail.com

Roseni dos Santos Miranda Mendonça

9249 3917/ e-mail: rosenymendonca@hotmail.com

1.2 - TURMA: H - PÓLO SANTA MARIA

\section{2 - DADOS DO PROJETO}

2.1 - TÍTULO

A IMPORTÂNCIA DA LEITURA PARA ELEVAR A AUTOESTIMA DOS ALUNOS DE EJA

2.2 - ÁREA DE ABRANGÊNCIA

LOCAL

2.3 - INSTITUIÇÕES

Escola Municipal João Gabriel

Conjunto $1 \mathrm{HI}$ área especial - centro

Escola Municipal Lago Azul

Quadra 51 lote 15/20 - Jardim Lago Azul - Novo Gama - GO

Instância institucional de decisão: Municipal

Todas as decisões serão tomadas a nível municipal através do Conselho Escolar.

2.4 - PÚBLICO

O Projeto de Intervenção Local visa atender aos alunos da Educação de Jovens e Adultos do segundo segmento das escolas Municipal João Gabriel e Lago Azul, município do 
Novo Gama. O público é composto de alunos e alunas trabalhadores, pessoas de meia idade, jovens que não tiveram acesso aos estudos, mães solteiras, migrantes que vieram de outras regiões para o entorno de Brasília e alunos com necessidades especiais. Temos percebido as dificuldades apresentadas, no que concerne, a dificuldades de leitura e interpretação e a baixa autoestima apresentada pelos alunos quando retomam os estudos. $O$ objetivo é incentivar a leitura através da conscientização e reflexão dos alunos para valorizar a educação como meio de crescimento humano e profissional.

\section{5 - PERÍODOS DE EXECUÇÃO}

Início: agosto/2010

Término: novembro/2010

\section{3 - AMBIENTE INSTITUCIONAL}

A Escola Municipal Lago Azul foi inaugurada em 10 de junho de 1992. Em 1998 iniciou o trabalho com a educação de jovens e adultos, atendendo alunos do sexto ao nono ano do Ensino Fundamental. A escola foi criada para atender a comunidade do Jardim Lago Azul, ainda muito carente de serviços públicos, um dever do Estado (CF/88) da família e da sociedade, com qualidade para os moradores.

O trabalho da instituição é o de possibilitar escolaridade de Ensino Fundamental I, primeiro ao quinto ano no período diurno, e Educação de Jovens e Adultos durante o período noturno.

A clientela de alunos da EJA é constituída de jovens, pessoas de meia idade e idosos que, em sua maioria, não tiveram oportunidade de cursar o ensino regular, jovens que exercem atividades no mercado de trabalho, trabalhadores de diversos setores da economia e trabalhadoras do lar que carecem de uma formação escolar para obterem oportunidades para trabalharem, seja na iniciativa privada ou no setor público. Residem no Jardim Lago Azul Boa Vista, Esplanada e Lunabel, áreas abrangidas pela escola.

Em sua maioria são constituídos pela população de baixa renda, muitos trabalham em Brasília e devido às deficiências do transporte público oferecido a população e ao cansaço, ao final do dia, têm dificultado a freqüência diária na escola.

A Escola Municipal João Gabriel oferece o ensino básico Fundamental do primeiro ao quinto ano, no Ensino Regular, no período diurno e a Educação de Jovens e Adultos, Fundamental II no período noturno. 
Constata-se a presença de um público bastante misto relativo à idade, gênero, etnias, onde as expectativas e os objetivos de estudo são variáveis. Os mais jovens trazem os problemas que tiveram no ensino regular, como o desinteresse e a pouca valorização dos estudos. Entretanto, este público apresenta uma semelhança: pouco tempo para se dedicar aos estudos fora da sala de aula. Muitos possuem uma jornada longa e cansativa de trabalho, moram longe do serviço e da escola e, no caso das mães estudantes, têm de cuidar dos afazeres domésticos.

A escola foi criada para atender a comunidade do Bairro Pedregal e adjacências, no município do Novo Gama.

A comunidade onde estão inserida as duas escolas são, na sua maioria, migrantes do nordeste que procuram, em novas paragens, melhores condições de trabalho e de vida. Apresentam pouco estudo formal e dificuldades de aprendizagem, mas trazem consigo conhecimentos adquiridos na vivência, conhecimentos, estes, que não podem ser ignorados no ambiente escolar.

As duas escolas apresentam uma boa estrutura física, podendo comportar os alunos com qualidade. Temos o apoio da direção e o auxílio dos auxiliares de educação para oferecer merenda para os alunos da EJA. As duas escolas carecem, com urgência, de material didático e de uma biblioteca que possibilitem para os alunos, lugar de leitura e pesquisa. Um espaço, com monitores, onde as mães estudantes possam deixar seus filhos para assistirem as aulas. A direção da escola está encampando um projeto de arrecadação de livros com os alunos para enriquecer a biblioteca.

\section{4-JUSTIFICATIVA E CARACTERIZAÇÃO DO PROBLEMA}

Os alunos da Educação de Jovens e Adultos, geralmente, são pessoas vindas de famílias de baixa renda, filhos de pais que tiveram pouco estudo. Existem também aqueles que abandonaram os estudos devido à necessidade de trabalho para ajudar no rendimento familiar, não tendo condições de permanecer nas aulas na época de cursar o ensino regular.

Devido à necessidade de obter um certificado de formação, exigidas pelo mercado de trabalho, esses alunos procuram adquirir conhecimentos e cultura, em busca de sua autoestima, transformando-se em sujeitos de suas ações.

Para Jennifer Rogers, em seu livro Ensino de Adultos (1976.p.13), "os estudantes adultos vêm à escola por motivos de realização e recompensa, necessidade de sentir-se bom em alguma coisa".

Para o educador Paulo Freire no seu livro Pedagogia da Autonomia (1996. p23), 
"não há docência sem discência, as duas se explicam e seus sujeitos apesar das diferenças que os conotam, não se reduzem à condição de objeto, um do outro. Quem ensina aprende ao ensinar e quem aprende ensina ao aprender. Compreendemos que as funções dos educadoresdevem ser a intermediação de conhecimentos respeitando os saberes que os educandos adquirem no cotidiano, valorizar este saber e aprender com os alunos. O educador Paulo Freire nos orienta a respeitar os saberes dos

educandos, principalmente das classes populares que possuem saberes construídos na prática comunitária, aproveitarem a experiência que têm os alunos de viver em áreas descuidadas pelo poder público, os baixos níveis de bem-estar da comunidade, as implicações políticas e ideológicas do descaso das classes dominantes pelas áreas pobres da cidade".

Incentivar o debate acerca da importância da leitura e da baixa autoestima, nas escolas, possibilitará reflexões na percepção e na compreensão que os alunos poderão desenvolver uma consciência política, podendo cobrar o que lhes é de direito resguardado pela Constituição Cidadã de 1998.

Em nossa sociedade, a busca pela informação, ato de informar conjunto de fatos, de noções, que existem em determinado momento sobre determinado assunto, e pelo conhecimento, conjunto de informações que inclui crenças e valores que se modificam de acordo com o meio em que as pessoas vivem, tem sido um processo contínuo, seja pela percepção de que sem eles o indivíduo ficaria excluído socialmente, ou seja, de que, com estes, não permaneceria no estado de ignorância neste novo contexto informacional, marcado visivelmente pelo uso intensivo das tecnologias da informação e de comunicação.

O conhecimento pode ser adquirido e construído através da prática da leitura, incentivando os alunos e os professores a terem prazer na arte de ler, e esta, por sua vez, possibilita formar uma sociedade consciente de seus direitos e deveres; possibilita que estes tenham uma visão melhor do mundo e de si mesmos.

Sabemos que ao longo das gerações passadas o fracasso escolar se deu por vários motivos que foram frutos de uma educação baseada no método tradicionalista, onde aluno era visto como mero receptor de conhecimentos e seu papel, neste modelo de educação, era desempenhar atividades de repetição não sendo incentivada sua participação.

Para o educador Paulo Freire na sua obra Pedagogia do Oprimido (p.66,67), 
"a narração de que o educador é o sujeito, conduz os educandos à memorização mecânica do conteúdo narrado. Mais ainda, a narração os transforma em vasilhas, em recipientes a serem enchidos pelo educador. Quanto mais vá enchendo os recipientes com seus depósitos, tanto melhor educador será. Quanto mais se deixem docilmente encher, tanto melhores educandos serão". Na visão bancária da educação, "o saber é uma doação dos que se julgam sábios aos que julgam nada saber. Doação que se funda numa das manifestações instrumentais da ideologia da opressão - a absolutização da ignorância, que constitui o que chamamos de alienação da ignorância, segundo a qual esta se encontra sempre em outro".

Diante deste contexto são necessárias novas maneiras de intermediação do conhecimento baseada na respeitabilidade dos conhecimentos que os alunos trazem consigo. O educador Paulo Freire (1981, p.79) compreende que, "ninguém educa ninguém, como tampouco ninguém se educa a si mesmo: os homens se educam em comunhão, mediatizados pelo mundo".

Atualmente vivemos um novo período na educação brasileira que objetiva formar nos educandos novos hábitos e atitudes que resultam na sua plena participação, na construção do seu conhecimento, tornando-o sujeito da própria aprendizagem.

A escola para ser de boa qualidade precisa transmitir construir e produzir conhecimentos vivos, dinâmicos e atuais, sem, contudo deixar de considerar o conhecimento e o interesse dos seus educandos. Deve garantir a aquisição dos conteúdos sistematizados atuais, garantir também, a formação política e o despertar da consciência crítica dos educandos, formandos cidadãos livres, autônomos, capazes de interferir em sua realidade e colocarem-se como protagonistas de sua história.

A democratização da sociedade brasileira e, especificamente, da educação, dar-se-á não apenas pela garantia de acesso a escola, mas também da permanência e do sucesso do educando. A escola precisa cumprir sua função social.

O aluno é sujeito da ação de aprender, aquele que age sobre o conhecimento, é nesse enfoque teórico concebido como prática educacional que organiza a mediação entre o sujeito e o objeto do conhecimento.

Devemos assumir responsabilidades com o processo de ensino/ aprendizagem no contexto sócio-político, de motivações, de formação de convicções, de afetos significativos de valores e desejos. Com isso poderemos promover profundas mudanças no modelo de ensino tradicional em busca de novos paradigmas educacionais. 
Podemos considerar a educação como um meio que busca esclarecer dúvidas do estudante no sentido de abranger sua capacidade de conhecer a si mesmo e o outro, podendo proporcionar a tomada de decisões, o pensar e o sentir, considerando todas as dimensões do homem no seu contexto de convivência.

O processo de educação busca, também, desenvolver no educando, conceitos e valores morais, respeitando o desejo, o prazer e a plena expressão do indivíduo, considerando o conhecimento adquirido através do ato de ler com visão crítica e reflexiva, valorizando o crescimento intelectual e possibilitando que os estudantes tenham um sentimento de que se é uma pessoa com valor e com direito de ser reconhecida por outros, melhorando a autoestima pessoal perante a sociedade.

A escola tem o objetivo de propiciar conhecimentos para os educandos desenvolvendo a capacidade intelectual, a percepção crítica, a capacidade de julgar e de obter comportamentos adequados ao meio onde vive. Oferecer a socialização para que enfrente o cotidiano, o trabalho e a relação com as outras pessoas.

A escola é o local fundamental para proporcionar a troca de experiências e tem como objetivo, oferecer aos alunos espaço para discussão, conhecimento e vivência de temas ligados a realidade de cada um e que promova, em todos os componentes curriculares, a formação de alunos críticos, participativos, dinâmicos e criativos objetivando o pleno exercício da cidadania.

Acreditamos que os estudantes, a partir de um conhecimento mais aprofundado, conscientizados e reflexivos, terão possibilidades de angariar melhores condições de emprego, conhecimentos críticos - políticos e sociais.

Este projeto se justifica pela necessidade de melhorar o nível de educação oferecida às comunidades carentes onde as escolas estão inseridas, possibilitar a construção coletiva do conhecimento com educação de qualidade onde o poder público assuma sua responsabilidade na oferta de educação básica de jovens e adultos. Compreendemos que o ato da leitura oferece grandes possibilidades de crescimento intelectivo sendo um gerador de incentivo a autoestima dos alunos, ato de apreciar-se como pessoa, darem-se valor, sentirem-se bem consigo mesma. Ter um conceito positivo de si através da capacidade e compreensão da leitura de textos com mais segurança, reflexão e criticidade isto possibilitará que se sintam valorizados perante a comunidade. 


\section{5 - OBJETIVOS}

\section{1-OBJETIVO GERAL}

Possibilitar aos estudantes práticas do hábito e incentivo à leitura, de aprofundar conhecimentos com qualidade e reflexão na perspectiva que aumentem sua autoestima.

\section{2-OBJETIVOS ESPECÍFICOS}

Possibilitar, para os educandos, plena capacidade de exercer sua cidadania na construção de uma sociedade melhor, através da prática da leitura e interpretação de textos com reflexão.

Proporcionar nos educandos a percepção de uma nova maneira de ler o mundo que os cercam.

Promover o desenvolvimento da aprendizagem e a socialização dos educandos, tendo a escola como espaço de formação e informação a fim de propiciar a inserção de adultos e jovens na realidade social.

Evitar o fracasso escolar, investindo em efetivo uso da leitura planejada, orientada pelo professor em níveis graduais de complexidade.

Enfatizar o papel ativo do leitor em sua interação com o texto e com o mundo, assumindo um papel atuante deixando de ser mero codificador ou receptor passivo.

\section{6 - ATIVIDADES/RESPONSABILIDADES}

O projeto VOCÊ ESCREVE SUA HISTÓRIA - FEIRA DO LIVRO será desenvolvida nas escolas onde ocorrerão várias atividades com o objetivo de incentivar a leitura e aumentar a valorização do estudante como ser participativo e construtor da história.

O projeto tem como objetivo levar jovens e adultos a se renderem ao mundo da magia, encanto e saber da leitura, explorando todas as formas de escrita e leitura, buscando contribuir para a formação da cidadania e acima de tudo, construir um país de leitores.

As atividades serão coordenadas pelos professores e desenvolvidas pelos alunos. Cada professor/professora ficará responsável pelo seu componente curricular e por uma turma de alunos onde serão desenvolvidos os trabalhos.

A proposta da Feira do Livro, nas escolas abrangidas pelo projeto, será a culminância de todo o trabalho desenvolvido pelos alunos durante a fase de pesquisa e estruturação das atividades propostas pelos professores coordenadores com o objetivo de incentivar a leitura na Educação de Jovens e Adultos. 
No componente curricular de história será desenvolvida a confecção de um livro biográfico pelos alunos, onde poderão utilizar fotos, cartões postais da região de onde procedem haja vista que muitos migraram da região nordeste para o entorno de Brasília, entrevistas com familiares, relatar a história cronológica da vida de cada aluno.

No componente curricular de geografia os alunos poderão fazer uma pesquisa sobre a origem do Município do Novo Gama, se foi uma cidade planejada, como o meio ambiente foi afetado, a formação vegetal da região, se atualmente existe projetos de preservação ambiental, a situação das nascentes no município. Dados geográficos sobre população, educação, saúde, lazer e segurança. Poderão ser utilizadas fotos antigas da cidade, entrevistas com pioneiros, confecção de cartazes com informações sobre os resultados da pesquisa.

No componente curricular de matemática os alunos poderão fazer uma pesquisa sobre as idéias teóricas que possibilitaram conceber as fórmulas, cálculos, raciocínio-lógico, enfim, um conhecimento abrangente e instigador sobre a matemática. A pesquisa será orientada pelo professor sobre quais autores pesquisar e o trabalho será realizado pelos alunos e apresentado na feira do livro.

No componente curricular de português será trabalhada com os alunos a pesquisa de textos literários, contos, prosas. Posteriormente os alunos farão uma releitura e resenha sobre os respectivos livros lidos, de acordo com cada compreensão textual.

$\mathrm{Na}$ área de arte serão trabalhadas fábulas com viés interpretativo de pesquisa e dramatização, confecção de tangram, uma espécie de quebra - cabeça onde os alunos irão confeccionar figuras diversas e após este trabalho, formular um texto sobre a peça desenvolvida pelos alunos.

No componente de ciências, sobre a coordenação da professora, os alunos irão confeccionar cartazes informativos sobre o aquecimento global, maneiras de evitar o desperdício de água e como, com pequenas atitudes, poderemos conscientizar a população da importância de preservarmos o meio ambiente e possibilitando um futuro melhor para a humanidade.

$\mathrm{Na}$ área de educação física serão realizadas, pelos alunos, pesquisas de textos sobre a importância da prática educativa no cotidiano das pessoas, cartazes ilustrativos de como praticar atividades físicas objetivando uma vida mais saudável.

No componente de inglês os alunos, coordenados pela professora, irão pesquisar o uso da linguagem anglo-saxônica no dia a dia e as influências no cotidiano da sociedade.

Nos componentes de filosofia e religião os alunos irão pesquisar as influências filosóficas na construção das diversas religiões e a história das inúmeras religiões inseridas na sociedade. 


\section{7 - CRONOGRAMA}

O projeto VOCÊ ESCREVE SUA HISTÓRIA - FEIRA DO LIVRO será realizada no segundo semestre de 2010, entre os meses de agosto e novembro, quando teremos a realização da feira do livro.

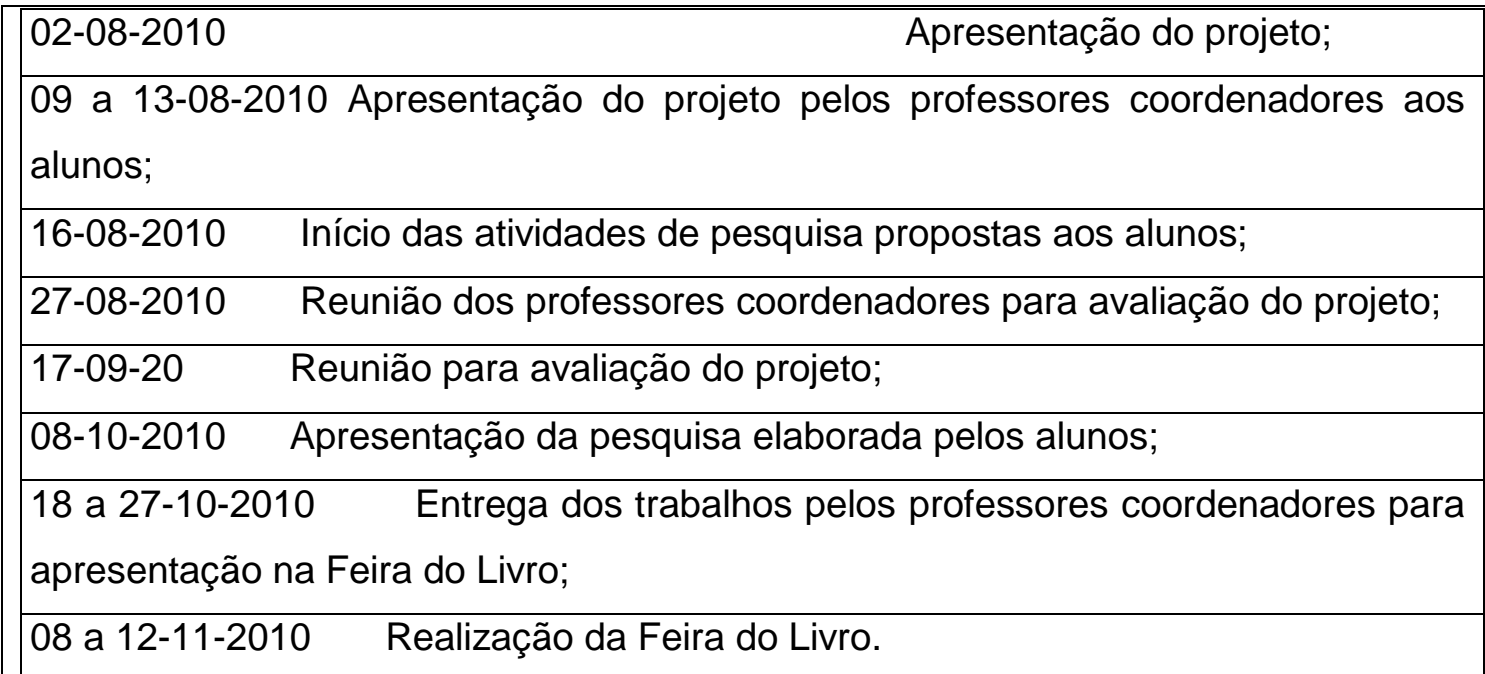

\section{8 - PARCEIROS}

O projeto será desenvolvido com a direção da escola, os professores coordenadores, os auxiliares em educação e a pesquisa que será feita pelos alunos para a confecção dos trabalhos.

\section{9 - ORÇAMENTO}

Os recursos para o projeto da feira do livro terão a participação da escola e dos alunos para a aquisição de materiais de uso para confeccionar os cartazes, peças teatrais, entrevistas que serão feitas com a participação da comunidade escolar.

Serão utilizados os seguintes materiais:

$\begin{array}{ll}\text { Cartolina } & 20,00 ; \\ \text { Papel cartão } & 30,00 ; \\ \text { TNT } & 50,00 ; \\ \text { Tapetes } & 50,00 ; \\ \text { Almofadas } & 70,00 ;\end{array}$


Papel ofício 50,00;

Pincéis 20,00;

Balões 20,00;

Mesas e cadeiras;

Vídeo e DVD, já disponíveis na escola.

\section{0 - ACOMPANHAMENTO E AVALIAÇÃO}

Todo o trabalho será feito sob a supervisão dos professores coordenadores, cada parte do projeto será avaliado permanentemente e ao longo da preparação para a feira do livro. Serão avaliados a participação e o empenho dos alunos na confecção dos trabalhos, o interesse do alunado na aprendizagem de novos conhecimentos.

Os alunos serão avaliados nas reuniões que acontecerão durante o percurso do projeto. Ao final irão apresentar seminários e mesas de debate onde cada aluno terá oportunidade de externar os conhecimentos assimilados durante o andamento do projeto.

\section{REFERÊNCIAS BIBLIOGRÁFICAS}

CÉLIA, Maria Borges Dalbério. Gestão democrática e participação na escola pública. Universidade Federal de Uberlândia, Minas Gerais, Brasil.

PAULO, Freire. Pedagogia da Autonomia: saberes necessários à prática educativa. São Paulo, 1996.

FREIRE, Paulo. Pedagogia do Oprimido. Rio de Janeiro, 1981.

ROGERS, Jennifer. - Ensino de Adultos, Lisboa, 1976. 